\title{
The Course of Induced Crying Activity in the First Year of Life
}

\author{
V. R. FISICHELLI, ${ }^{(48)}$ S. KARELITZ, R. M. FISICHELLI, AND J. COOPER \\ Department of Pediatrics, Long Island Jewish-Hillside Medical Center, New Hyde Park, and Department of \\ Psychology, Herbert Lehman College, City University of New York, New York, New York, USA
}

\section{Extract}

In the first year of life the crying response to painful stimulation varies with age, or more precisely as a function of those psychophysical processes which underlie changes in age. At $5 \mathrm{hr}$ of age crying reactivity is depressed from earlier age levels. It then increases at 2 days of age, remains relatively stable to 12 weeks of age, and thereafter diminishes markedly. Although the reliability coefficients from age to age show little or no stability of relative position for individual subjects, the course of crying reactivity generally shows significant differences from age group to age group.

That the course of the cry reaction curves is primarily a function of age is supported by additional findings reported here which rule out as major determinants systematic adaptation effects, sex differences, and gross differences in IQ levels within the group studied.

\section{Speculation}

Since crying activity, in one form or another, has been used as a response measure in many research investigations, the present study will offer guidelines regarding expected cry reactions from normal infants at a given age level. This study should make clear to the clinician that the same criteria cannot be used to evaluate the cry across the entire span of the first year of life. The same cry response, or lack of it, may be expected at one age and not at another. Since neurologic examinations frequently include response to painful stimulation, the age of the subject, with regard to the type of response studied here, becomes a critical factor in the diagnostic situation.

In the past decade, crying activity in the neonate has come under investigation in a variety of ways. Initially it was studied by Karelitz et al. (25) as a possible diagnostic tool for brain damage and as a part of the general development of infant vocalizations. Additional studies along these lines followed $(9-12,21,28,35,44)$. Subsequently, crying activity appeared as a response measure in studies related to Apgar evaluation (24), speech and intellectual development (23), mother-infant interactions $(5,16,31)$, maternal responsiveness $(3,36)$, maternal anxiety (33), social reinforcement $(20,39)$, accommodation to the nipple (7), twin differences (29), waking states (2), continuous stimulation (6), narcotic-addicted mothers (4), drug effects during labor $(26,41)$, and as part of a hearing test (32).

Although specific characteristics of the cry, auditive and spectrographic, have been identified and measured in some of these studies, there are relatively few investigations which deal directly with the nature of the cry itself $(14,35,37)$, or which offer, even indirectly, longitudinal guidelines describing the cry or the sensitivity level of the infant at different ages. One such study by the present authors (15) indicates, for example, that the infant near $5 \mathrm{hr}$ of age tends to be relatively less sensitive to painful stimulation than at earlier age levels and cries very little. Other investigators have shown that crying tends to decline at 3 months of age and more so at 6 months (3), and that reflexive crying varies somewhat with seasonal changes (39).

Apart from crying activity, the question of pain sensitivity in the infant has received little attention (34). The problems attendant upon such studies are numerous. Among them are the general unacceptability to both investigators and parents of the use of such pain-evoking stimuli as needle pricking, electric shock, and heat; and secondly, the difficulty in quantifying the intensity of painful stimuli. The technique of rubber band stimulation to the sole of the foot, used in this and in previous studies by the present investigators, was completely: acceptable to the parents. A method of quantifying the intensity of such stimulation (see Procedure) has been developed and analyzed (13).

The present longitudinal study is designed to provide data on the course of induced crying for the first year of life. It also provides information on changes in pain sensitivity, as reflected in crying, for the same period. The possibility that subjects who are stimulated repeatedly at successive ages might show adaptation effects was met by studying a control group of infants in a cross-sectional design; i.e., different infants were tested at each of the successive age levels.

\section{METHODOLOGY}

\section{SUBJECTS}

The 71 male and 87 female infants in this study were all normal full term infants born at the Long Island Jewish Hospital. Of these infants, 16 males and 22 females were tested longitudinally at successive ages from $5 \mathrm{hr}$ through 52 weeks of age. The 5-hr level was chosen as the starting point in order to confirm the lowered reactivity of infants at 4 and $6 \mathrm{hr}$ of age which was found in the previous investigation (15). The remaining infants, tested initially during their stay in the hospital nursery, were then studied cross-sectionally, only once thereafter, using different infants at the different age levels. This was done in order to preclude possible adaptation effects stemming from seriatim stimulation at successive age levels.

The infants in the longitudinal group were predominantly of Jewish parentage $(68 \%)$. One of the infants was Eurasian, the others Caucasian. The mean age of the mothers at the subjects' birth was 26 years (range 20-41), and the mean age of the fathers was 29 years (range 23-43). The mean birth weight in 
ounces was 116.7 (SD 13.9) for the males, and 114.2 (SD 13.2) for the females. The mean difference is not statistically significant (t 0.541 ). Apgar evaluation at $1 \mathrm{~min}$ of age showed 2 infants with a socre of 10,32 with scores of 8 or 9 , and two each with scores of 6 and 7.

In the longitudinal group of 38 unrelated infants, approximately half of the mothers listed themselves as housewives only, while the others listed varying degrees of outside occupational involvement, mostly teaching or nursing. Only five mothers and five fathers had no college training. Seventeen mothers and 25 fathers obtained college and higher degrees, including 2 M.D., 2 Ph.D., and 1 D.D.S. degrees among the fathers.

Although the crying activity phase of this research ended as the subjects reached 1 year of age, the infants in the longitudinal group were followed up to 3 years and 2 months of age, at which time the L-M form of the Third Revision of the Stanford-Binet Intelligence Test (42) was administered to them. These children had a mean IQ of 118.5 ; SD 16.3 which is significantly higher than the corrected mean of 109 for the 850 children reported by Terman and Merrill (t $3.500 ; P<$ $0.001)$. In the present sample, the mean for the girls was 122.1, SD 15.2, while the boys' mean was 113.6, SD 16.5. This difference was not statistically significant ( $t$ 1.593).

No special criteria were used in the selection of subjects for this study and no attempt was made to obtain a normative sample. Mothers were contacted through their obstetricians well in advance of delivery date and their informed consent was obtained in writing. No mother denied us her permission to study the anticipated infant. None of the subjects studied here are represented in previous investigations by the present authors.

\section{PROCEDURE}

The stimulus used to induce crying was suppled by the snap of a rubber band (RBS) stretched from its ordinary length of approximately $7.4 \mathrm{~cm}$ to about $23 \mathrm{~cm}$ on a gun-shaped stainless steel apparatus $17 \mathrm{~cm}$ long. The rubber band was attached to a notch on the bottom side of the gun and stretched around over the tip of it. The rubber band used was the Paar amber no. 32 (45), which has an impact force of 4.2 $\mathrm{mm}, \mathrm{SD}$ 1.2. Impact force is defined as the distance (millimeters) which a weight of $150 \mathrm{~g}$ is moved on a stainless steel surface when it is struck by the rubber band (13).

The infant's right leg and foot were exposed and the program of stimulation was begun. The examiner announced "Pick up foot," "Touch" as the stimulator was applied to the sole of the foot, and "One" as the stimulus was applied for the first time. If no crying followed within $10 \mathrm{sec}$, or if crying commenced but did not continue for $60 \mathrm{sec}$, stimulation was repeated until $1 \mathrm{~min}$ of crying was obtained, or a maximum of
3 RBS with rubber band no 32 were applied. In those instances when 3 RBS with no. 32 did not elicit 1 min of crying, a fourth and final RBS was used with a no. 30 rubber band. This rubber band has more sting to it. It has a mean impact force of $6.2 \mathrm{~mm}$; $\mathrm{SD} 1.0$, which is significantly different from the no. 32 band ( $4.500 ; P<0.01$ ), and the magnitude of its experimental effect (18) is appreciable $\left(R_{m}>\right.$ 0.80 ). All sessions were terminated when 1 min of crying was obtained or after the fourth RBS. Brief interruptions in the cry, usually 2 or $3 \mathrm{sec}$, were allowed in the 1 -min period, but the examiner waited for $10 \mathrm{sec}$ of silence before repeating the RBS. A new rubber band was used for each subject. No infant was tested within $30 \mathrm{~min}$ of his last feeding. All test sessions were recorded on magnetic tape.

Cry samples were obtained at the following ages for the longitudinal subjects: $5 \mathrm{hr}, 2$ and 4 days in the hospital nursery, and at $2,4,6,8,12,16,26,39$, and 52 weeks of age in their homes. Testing with the cross-sectional subjects was begun at 4 weeks of age and continued for the same age levels as in the longitudinal group but with a new sample of subjects at each successive age level.

In this extensive activity we were assisted by a group of volunteers from the hospital's Womens Service Guild. The women in this group of volunteers have been associated with the cry project for many years. They were carefully trained to make the tape recordings and to help in the collection of the necessary data.

Simner (39) has reported that there are seasonal variations in reflexive crying. Such effects are precluded in this study since the subjects were started at different times in the calendar year. In the longitudinal group, 14 subjects were started in the winter, 7 in the fall, 10 in the spring, and 7 in the summer. The cross-sectional subjects at any age level also were tested at different times of the calendar year.

\section{MEASURES}

The tape recordings of each test session were played to three auditors who translated them into the following measures: (1) latency, in tenths of a second, from the audible snap of the stimulus to the first vocalization of the infant. Latency is always taken from the first RBS only, since this is the stimulus common to all subjects, (2) total number of sounds but not including gasps, (3) cumulative time spent in crying, and (4) the number of gasps, where gasp is defined as a phonated inhalation after the single bursts of the cry. The last three measures, sounds, cumulative time, and gasps, were recorded for each RBS, and the data obtained from the RBS which produced the longest cumulative crying time were used in the analysis. Since many of the infants did not require the more intense stimulus, no. 30 , it could not be used as a uniform standard. The occurrence of no response to RBS no. 1

Table 1. Interrelations (Pearson r) among cry measures at 2 weeks of age

\begin{tabular}{|c|c|c|c|c|c|c|c|}
\hline & \multirow[b]{2}{*}{$\mathrm{N}$} & \multicolumn{2}{|c|}{ Total sounds without gasps } & \multicolumn{2}{|c|}{ Cumulative time } & \multicolumn{2}{|c|}{ Gasps } \\
\hline & & $\mathrm{r}$ & $P^{\mathbf{i}}$ & $\mathrm{r}$ & $P$ & $\mathrm{r}$ & $P$ \\
\hline \multicolumn{8}{|l|}{ Latency } \\
\hline Male & 15 & -0.62 & 0.01 & -0.64 & 0.01 & -0.29 & N.S. ${ }^{2}$ \\
\hline Female & 21 & -0.66 & 0.001 & -0.61 & 0.005 & -0.38 & 0.05 \\
\hline \multicolumn{8}{|c|}{ Total sounds } \\
\hline Male & 15 & & & 0.80 & 0.0005 & 0.73 & 0.005 \\
\hline Female & 22 & & & 0.75 & 0.00005 & 0.50 & 0.01 \\
\hline \multicolumn{8}{|c|}{ Cumulative time } \\
\hline Male & 15 & & & & & 0.62 & 0.01 \\
\hline Female & 22 & & & & & 0.41 & 0.05 \\
\hline
\end{tabular}

${ }^{1}$ All $P$ values are one-tail and taken from the Sockloff and Edney extensions (40).

${ }^{2}$ Not significant. 
Table 2. Statistical summary of cry measures according to group and sex

\begin{tabular}{|c|c|c|c|c|c|c|c|c|c|c|c|c|}
\hline & \multicolumn{12}{|c|}{ Latency, sec } \\
\hline & $5 \mathrm{hr}$ & 2 days & 4 days & $2 \mathrm{wk}$ & $4 \mathrm{wk}$ & $6 \mathrm{wk}$ & $8 \mathrm{wk}$ & $12 \mathrm{wk}$ & $16 \mathrm{wk}$ & $26 w k$ & $39 \mathrm{wk}$ & $52 \mathrm{wk}$ \\
\hline \multicolumn{13}{|l|}{ Longitudinal } \\
\hline \multicolumn{13}{|l|}{ Male } \\
\hline $\mathrm{N}$ & 8 & 11 & 12 & 14 & 7 & 11 & 11 & 10 & 6 & 6 & 4 & 3 \\
\hline Mean & 1.98 & 1.43 & 1.56 & 1.57 & 1.64 & 1.55 & 1.89 & 1.95 & 1.47 & 1.58 & 2.32 & 1.07 \\
\hline SD & 0.72 & 0.30 & 0.35 & 0.59 & 0.46 & 0.80 & 0.62 & 0.75 & 0.73 & 0.49 & 1.10 & 0.05 \\
\hline \multicolumn{13}{|l|}{ Female } \\
\hline $\mathrm{N}$ & 20 & 14 & 10 & 19 & 16 & 16 & 14 & 11 & 11 & 10 & 8 & $7:$ \\
\hline Mean & 1.70 & 1.57 & 1.57 & 1.58 & 1.31 & 1.70 & 1.46 & 1.86 & 1.92 & 1.85 & 2.10 & 1.61 \\
\hline $\mathrm{SD}$ & 0.37 & 0.41 & 0.41 & 0.73 & 0.30 & 0.90 & 0.85 & 0.53 & 0.91 & 0.59 & 0.79 & 0.89 \\
\hline \multicolumn{13}{|c|}{ Mann-Whitney tests (M vs. F): none significant } \\
\hline \multicolumn{13}{|c|}{ All longitudinal } \\
\hline $\mathrm{N}$ & 28 & 25 & 22 & 33 & 23 & 27 & 25 & 21 & $17:$ & 16 & 12 & 10 \\
\hline Mean & 1.78 & 1.51 & 1.56 & 1.59 & 1.41 & 1.64 & 1.65 & 1.90 & 1.76 & 1.75 & 2.18 & 1.45 \\
\hline Median & 1.70 & 1.50 & 1.50 & 1.40 & 1.40 & 1.50 & 1.60 & 1.90 & 1.60 & 1.50 & 2.00 & 1.11 \\
\hline SD & 0.51 & 0.37 & 0.38 & 0.68 & 0.39 & 0.87 & 0.79 & 0.65 & 0.88 & 0.57 & 0.89 & 0.78 \\
\hline \multicolumn{13}{|c|}{ All cross-sectional } \\
\hline $\mathrm{N}$ & & & & & 9 & 11 & .11 & 11 & 5 & 8 & 4 & 5 \\
\hline Mean & & & & & 1.62 & 1.60 & 1.81 & 1.70 & 1.78 & 2.29 & 2.65 & 1.76 \\
\hline Median & & & & & 1.40 & 1.50 & 1.60 & 1.90 & 1.60 & 2.00 & 2.75 & 1.50 \\
\hline SD & & & & & 0.49 & 0.43 & 0.67 & 0.83 & 0.35 & 0.59 & 0.38 & 0.38 \\
\hline \multicolumn{13}{|c|}{ Mann-Whitney tests (L vs. XS): none significant } \\
\hline
\end{tabular}

Table 3. Statistical summary of cry measures according to group and sex

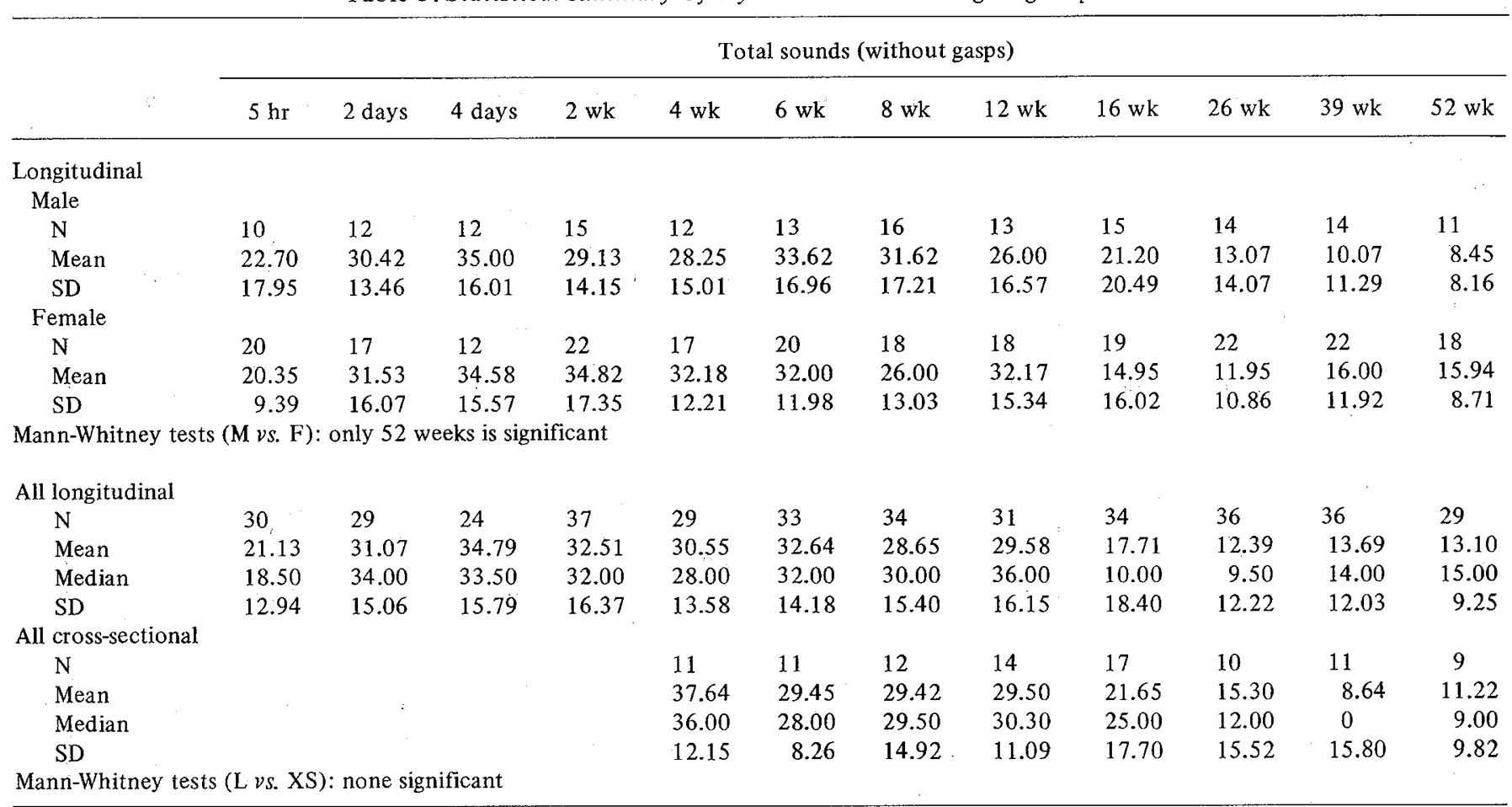

was recorded separately as an additional measure of sensitivity to painful stimulation.

Differences among the scores of the three auditors were small but the mean values of their scores were used nonetheless. Interauditor correlation coefficients varied from 0.91 to 0.96 .

\section{RESULTS}

An analysis of the interrelation of the basic measures at 2 weeks of age (where the largest number of subjects responded) is found in Table 1, where it will be seen that the various measures have certain elements in common, but not enough to warrant substituting one measure for another, with the possible exception of total sounds and cumulative time. All but one of the correlation coefficients are statistically reliable at least at the one-tail 5\% level. The negative values for latency are in the predicted direction; i.e., the faster the reaction to the stimulus, the more productive is the cry, and the longer it lasts.

The substantive findings of this study are summarized in Tables $2-5$, in which are given the descriptive statistics and significance levels at each age level for males, females, all subjects of the longitudinal study combined, and for the separate groups of the cross-sectional series. It should be noted that the latency values apply only to RBS 1 since this stimulus was common to all subjects. Also, the means are based only on 
Table 4. Statistical summary of cry measures according to group and sex

\begin{tabular}{|c|c|c|c|c|c|c|c|c|c|c|c|c|}
\hline & \multicolumn{12}{|c|}{ Cumulative time, sec } \\
\hline & $5 \mathrm{hr}$ & 2 days & 4 days & $2 \mathrm{wk}$ & $4 \mathrm{wk}$ & $6 \mathrm{wk}$ & $8 \mathrm{wk}$ & $12 \mathrm{wk}$ & $16 \mathrm{wk}$ & $26 \mathrm{wk}$ & $39 \mathrm{wk}$. & $52 \mathrm{wk}$ \\
\hline \multicolumn{13}{|l|}{ Longitudinal } \\
\hline \multicolumn{13}{|c|}{ Male } \\
\hline $\mathrm{N}$ & 10 & 12 & 12 & 15 & 12 & 13 & 16 & 14 & 15 & 14 & 14 & 11 \\
\hline Mean & 35.60 & 48.92 & 52.50 & 46.33 & 46.25 & 47.85 & 47.62 & 43.79 & 29.13 & 22.36 & 22.07 & 24.18 \\
\hline SD & 21.13 & 17.89 & 15.00 & 20.23 & 19.03 & 19.59 & 21.64 & 25.30 & 26.83 & 24.39 & 23.77 & 26.33 \\
\hline \multicolumn{13}{|l|}{ Female } \\
\hline $\mathrm{N}$ & 20 & 17 & 12 & 22 & 17 & 20 & 18 & 18 & 19 & 22 & 22 & 18 \\
\hline Mean & 39.30 & 45.59 & 49.92 & 49.50 & 52.35 & 52.10 & 43.50 & 48.39 & 24.95 & 25.32 & 41.68 & 44.50 \\
\hline SD & 14.87 & 18.26 & 15.41 & 18.79 & 12.61 & 15.55 & 19.56 & 21.63 & 26.19 & 24.05 & 25.51 & 20.85 \\
\hline \multicolumn{13}{|c|}{ Mann-Whitney tests (M vs. F): only 39 weeks is significant } \\
\hline \multicolumn{13}{|c|}{ All longitudinal } \\
\hline $\mathrm{N}$ & 30 & 29 & 24 & 37 & 29 & 33 & 34 & 32 & 34 & 36 & 36 & 29 \\
\hline Mean & 38.07 & 46.97 & 51.21 & 48.22 & 49.83 & 50.42 & 45.44 & 46.38 & 26.79 & 24.17 & 34.06 & 36.79 \\
\hline Median & 41.00 & 57.00 & 60.00 & 55.00 & 57.00 & 60.00 & 57.00 & 60.00 & 20.00 & 15.50 & 50.50 & 45.00 \\
\hline $\mathrm{SD}$ & 17.30 & 18.18 & 15.26 & 19.45 & 15.88 & 17.38 & 20.67 & 23.42 & 26.56 & 24.23 & 26.62 & 25.10 \\
\hline \multicolumn{13}{|c|}{ All cross-sectional } \\
\hline $\mathrm{N}$ & & & & & 11 & 11 & 12 & 14 & 17 & 10 & 11 & 9 \\
\hline Mean & & & & & 55.91 & 59.36 & 49.58 & 53.93 & 32.35 & 24.20 & 15.27 & 29.00 \\
\hline Median & & & & & 60.00 & 60.00 & 60.00 & 60.00 & 25.00 & 12.00 & 0 & 9.00 \\
\hline $\mathrm{SD}$ & & & & & 10.41 & 1.37 & 20.13 & 14.28 & 24.55 & 24.25 & 22.75 & 25.18 \\
\hline
\end{tabular}

Table 5. Statistical summary of cry measures according to group and sex

\begin{tabular}{|c|c|c|c|c|c|c|c|c|c|c|c|c|}
\hline & \multicolumn{12}{|c|}{ Gasps } \\
\hline & $5 \mathrm{hr}$ & 2 days & 4 days & $2 \mathrm{wk}$ & $4 \mathrm{wk}$ & $6 \mathrm{wk}$ & $8 \mathrm{wk}$ & $12 \mathrm{wk}$ & $16 \mathrm{wk}$ & $26 \mathrm{wk}$ & $39 \mathrm{wk}$ & $52 \mathrm{wk}$ \\
\hline \multicolumn{13}{|c|}{ Longitudinal } \\
\hline \multicolumn{13}{|c|}{ Male } \\
\hline $\mathrm{N}$ & 10 & 12 & 12 & 15 & 12 & 13 & 16 & 13 & 15 & 14 & 14 & 11 \\
\hline Mean & 7.70 & 15.92 & 9.58 & 9.87 & 6.75 & 6.62 & 8.94 & 6.00 & 7.07 & 1.86 & 3.86 & 3.45 \\
\hline SD & 10.24 & 12.59 & 6.76 & 9.41 & 6.92 & 7.56 & 10.27 & 9.70 & 12.66 & 4.41 & 5.01 & 4.14 \\
\hline \multicolumn{13}{|l|}{ Female } \\
\hline $\mathrm{N}$ & 20 & 17 & 12 & 22 & 17 & 20 & 18 & 18 & 19 & 22 & 22 & 18 \\
\hline Mean & 7.65 & 16.82 & 18.58 & 14.59 & 13.18 & 12.65 & 10.28 & 9.56 & 3.05 & 4.05 & 8.55 & 6.56 \\
\hline $\mathrm{SD}$ & 5.32 & 11.05 & 16.05 & 15.89 & 12.28 & 12.11 & 8.70 & 11.50 & 4.99 & 6.00 & 6.12 & 5.96 \\
\hline \multicolumn{13}{|c|}{ Mann-Whitney tests (M vs. F): none significant } \\
\hline \multicolumn{13}{|c|}{ All longitudinal } \\
\hline $\mathrm{N}$ & 30 & 29 & 24 & 37 & 29 & 33 & 34 & 31 & 34 & 36 & 36 & 29 \\
\hline Mean & 7.67 & 16.45 & 14.08 & 12.68 & 10.52 & 10.27 & 9.65 & 8.06 & 4.82 & 3.19 & 6.72 & 5.38 \\
\hline Median & 6.50 & 16.00 & 13.50 & 9.00 & 8.50 & 7.00 & 8.00 & 2.00 & 0 & 0 & 7.50 & 4.00 \\
\hline SD & 7.34 & 11.72 & 13.11 & 13.84 & 10.87 & 10.96 & 9.49 & 10.92 & 9.41 & 5.54 & 6.15 & 5.55 \\
\hline \multicolumn{13}{|c|}{ All cross-sectional } \\
\hline $\mathrm{N}$ & & & & & 11 & 11 & 12 & 14 & 17 & 10 & 11 & 9 \\
\hline Mean & & & & & 19.82 & 10.82 & 11.17 & 10.21 & 5.12 & 2.00 & 2.45 & 1.44 \\
\hline Median & & & & & 16.00 & 10.00 & 9.00 & 6.00 & 0 & 0 & 0 & 0 \\
\hline SD & & & & & 15.92 & 5.00 & 10.71 & 9.31 & 8.36 & 2.86 & 5.00 & 2.50 \\
\hline
\end{tabular}

those subjects who yielded a latency of $4.0 \mathrm{sec}$ or less. Anything greater than that is beyond 3 sigma units from the mean of 1.6, SD 0.75 , previously established (11), and those infants who gave no response at all were excluded from the description of mean latency in Table 2 and Fig. 2 on the grounds that they may have been clinically different from subjects who were merely slow to react.

The tables reveal three salient features concerning the course of painful sensitivity as reflected in crying activity during the first year of life: $(1)$ considerable variability among individual subjects within a given age group, (2) no major systematic differences between groups, whether male versus female or longitudinal versus cross-sectional, and (3) a period of lowered reactivity at $5 \mathrm{hr}$ of age which is followed by a higher and relatively stable interval lasting from 2 days to 12 weeks, with a subsequent falling off of reactivity up to the conclusion of the assay at 1 year of age (see Figs. $1-5$ ).

\section{DISCUSSION}

The marked variability among the subjects in all measures except latency is reflected in the standard deviations which are 
comparatively large with respect to their corresponding means. They are large enough, in that sense, to preclude standard normal curve interpretations. They are also large enough to make questionable the use of a variety of parametric tests in spite of their well advertised robustness (19). In any case, the two factor mixed design ANOVA around which this study was originally designed had to be abandoned because $\mathrm{N}$ varied unpredictably from age to age as one or another subject became unavailable in one or another of the 12 successive test sessions. Accordingly, nonparametric methods (38) were brought to bear on the analysis of the various differences.

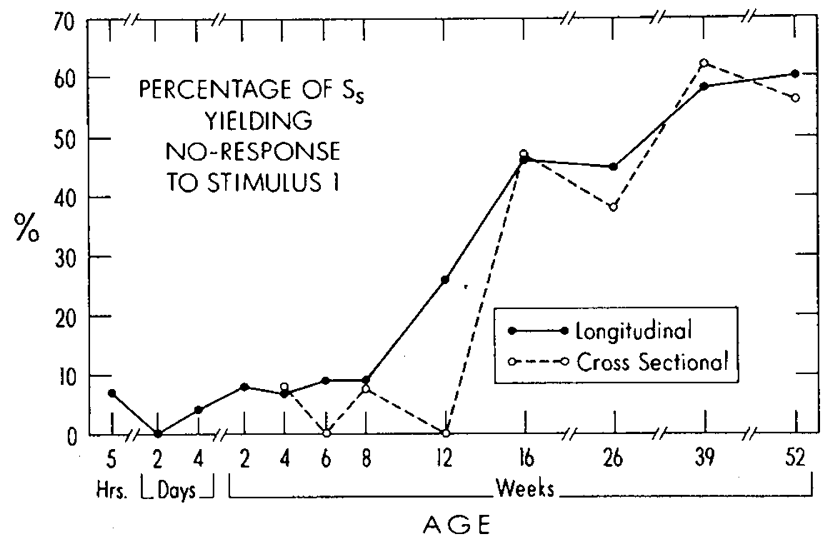

Fig. 1. The percentage of subjects in each design group who gave no response to stimulus 1 , at successive age levels.

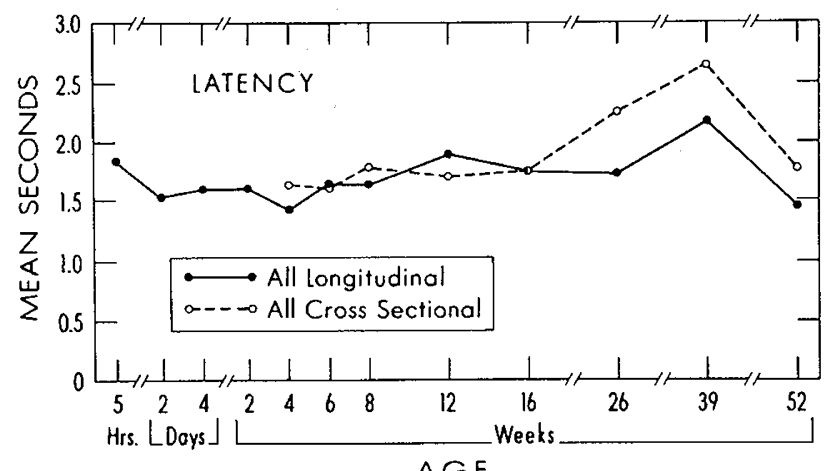

Fig. 2. The mean latency (in seconds) according to age and design group.

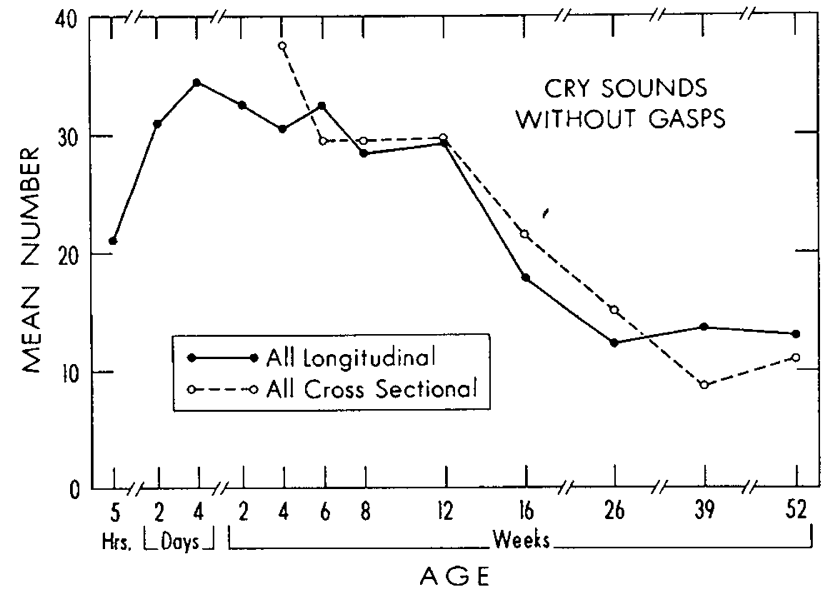

Fig. 3. The mean number of cry sounds, not including gasps, according to age and design group.

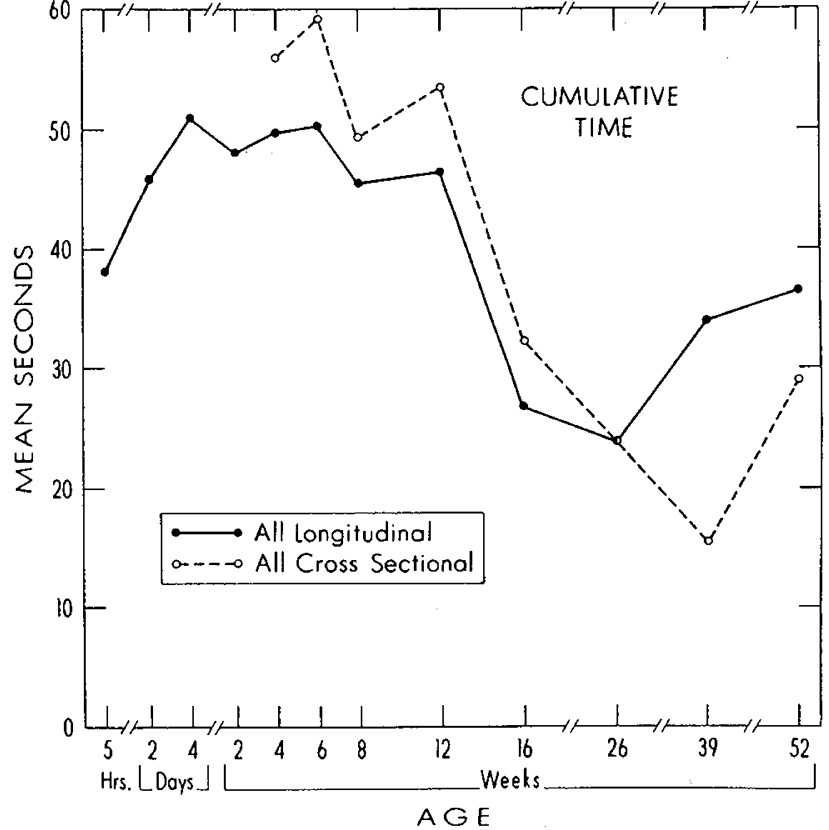

Fig. 4. The mean cumulative time (in seconds) spent in crying, according to age and design group.

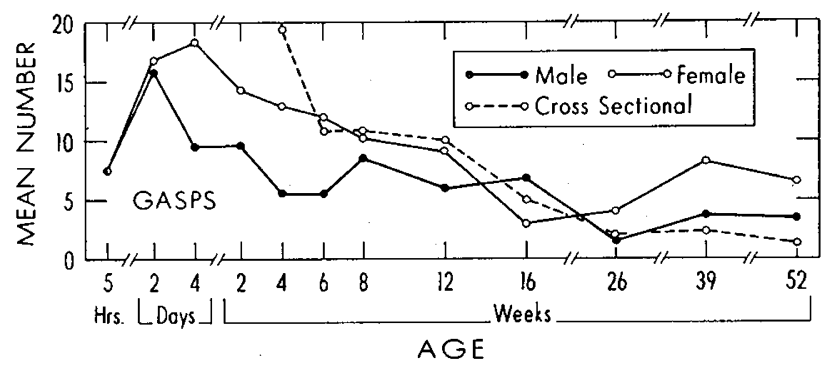

Fig. 5. The mean number of gasps according to age, and for the males and females of the longitudinal group.

One of the most easily observed changes in the development of the cry is the infant's response, or lack of it, when the first painful stimulus is applied. In Fig. 1 it will be seen that very few subjects $(10 \%$ or less) who are younger than 12 weeks of age fail to respond to the first stimulus. The speed of the reaction will be discussed below but it is clear that a marked decrease in responsivity occurs for both the longitudinal and cross-sectional design groups at 16 weeks of age, and thereafter. At 12 weeks of age, the incidence of no response is significantly greater in the longitudinal rather than the cross-sectional group (Fisher's exact $P 0.0510$, two tails). It would appear that the longitudinal subjects, because of their previous experiences with stimulation come to the point of not reacting vocally to RBS 1 sooner than their counterparts who had no such previous stimulation. This would seem to be a clear indication of an adaptation effect, but it is equally clear that it is not systematic since the effect is not found at 16 weeks or thereafter. Even at 12 weeks the effect is manifest only as a reaction to the first stimulus; i.e., once the cry is obtained from RBS 2 or 3, there are no statistically significant differences between the longitudinal and cross-sectional design groups with regard to total sounds, gasps, or cumulative time. In addition, the 21 longitudinal and 11 cross-sectional infants who did respond to RBS 1 at 12 weeks of age show no significant difference in mean latency.

In any case, it is a fairly common reaction not to cry in response to the first stimulus at 16 weeks of age and 
thereafter. Grimaces and struggling to get free as well as other motor reactions are visible but they occur without crying. One cannot escape the hypothesis that this lack of cry reaction is a maturing response and that it may be related to the corresponding maturation of central nervous processes within the individual at 3 or 4 months of age.

The mean latency at $5 \mathrm{hr}$ is significantly higher than it is at 2 days of age (Wilcoxon T 19,P 0.02.). This lowered level of reactivity at $5 \mathrm{hr}$ has already been referred to here and elsewhere (15). In this study the latency data clearly confirm that the 5-hr period is a depressed one for the infant, but the data also show that the infants are not so depressed as to fail to respond. Fig. 1 shows that less than $10 \%$ of the infants gave no response at all to RBS 1; thus, they respond, but more slowly than they do at 2 days of age.

It has been mentioned by several that the infant's state of arousal at the time of testing may be a variable which determines the intensity of his response. In the present study the question of state applied only to the first three test sessions which took place in the nursery of the hospital. The nine remaining test sessions were conducted in the subject's home where we tried to tape record noncrying vocalizations before the cry was obtained. In these latter sessions all subjects were fully awake. With regard to the cry samples obtained in the nursery, response differences were minimized to some extent by the procedure of using the longest cry response to each of the three stimuli. To wait for spontaneous wakefulness would alter the age variable which was rigorously adhered to, particularly in the newborn period. At $5 \mathrm{hr}$ of age most of the infants were asleep or sleepy. Their blankets and the sock of one foot were removed. They were placed on their backs if not already there and the program of stimulation was announced and initiated. To do more than this to one child rather than another would have compromised the constancy of the program of stimulation. Thus, the procedure employed here kept constant the 5-hr age level as well as allowing for a uniform program of stimulation designed to induce active crying (the highest state of arousal) as the subject matter for study.

In any case, our previous study (15) showed that under the same conditions, infants at 1 and $10 \mathrm{~min}$ of age and at $2 \mathrm{hr}$ of age were more responsive than they were at $4 \mathrm{hr}$ (low Apgar infants) and $6 \mathrm{hr}$ (high Apgar infants) of age.

The cause of this depression is not immediately clear to us. It may be due quite simply to sleepiness or to fatigue... "neurological fatigue" according to Desmond (8). The effort expended in the act of birth, the transition from placental to pulmonary breathing, the violent and sudden extension of the diaphragm, possible chilling in the immediate postnatal period, the type of delivery, perhaps even the sedative effects of analgesics or anesthetics administered to the mother in labor and delivery; all these, and other concomitant variables may contribute to the lowered reactivity of the infant at this age of life.

For total sounds (see Fig. 3) there were no significant sex differences except at 52 weeks (U 52.2, $P<0.05$ ). Here the females produced almost twice as many sounds as the males. None of the longitudinal and cross-sectional design group differences were statistically reliable, again indicating no overall adaptation effect. The period of relative stability for total sounds runs from 2 days to 12 weeks. Thereafter, the output of the cry diminishes and continues to fall to its lowest point at 1 year of age, the terminal point of this study. As shown in Fig. 4, cumulative time runs the same course. At 4 weeks of age, a greater number of cross-sectional rather than longitudinal subjects yielded the maximum time of $60 \sec \left(\chi^{2}\right.$ $4.514, P<0.05$, two tails). None of the remaining design group differences were significant, although the difference at 39 weeks, favoring the longitudinal subjects, comes close to significance (Z 1.865, P 0.063, two tails). (The only significant sex difference occurred at 39 weeks in favor of the girls $(Z$ $2.110, P 0.035$, two tails).

The gasping sound which follows a single burst of crying is not merely an inhalation of air, but rather it is a sudden intake which is strong enough to produce vocal chord vibration. The gasping sounds appear to be more characteristic of the younger infant and of the female rather than the male. For this reason the male and female scores are plotted separately in Fig. 5. However, when the sex differences were subjected to the Mann-Whitney tests, none were significant. Nevertheless, one is

Table 6. Intercorrelations (Pearson $r$ ) among age levels

\begin{tabular}{|c|c|c|c|c|c|c|c|c|c|c|}
\hline & \multicolumn{5}{|c|}{ Cry index } & \multicolumn{5}{|c|}{ Latency } \\
\hline & 4 days & $2 \mathrm{wk}$ & $12 \mathrm{wk}$ & $16 \mathrm{wk}$ & $52 \mathrm{wk}$ & 4 days & $2 \mathrm{wk}$ & $12 \mathrm{wk}$ & 16 wk & $52 \mathrm{wk}$ \\
\hline \multicolumn{11}{|l|}{ Male } \\
\hline $5 \mathrm{hr}$ & $0.90^{1}$ & -0.11 & 0.18 & -0.60 & -0.11 & $0.78^{2}$ & 0.17 & 0.13 & -0.44 & -0.12 \\
\hline 4 days & & -0.40 & -0.10 & -0.48 & $-0.68^{2}$ & & -0.14 & 0.21 & -0.07 & 0.14 \\
\hline 2 wk & & & $-0.68^{x}$ & 0.42 & -0.16 & & & -0.20 & 0.18 & -0.46 \\
\hline $12 \mathrm{wk}$ & & & & 0.18 & 0.33 & & & & 0.32 & 0.39 \\
\hline $16 \mathrm{wk}$ & & & & & 0.15 & & & & & 0.20 \\
\hline \multicolumn{11}{|l|}{ Female } \\
\hline $5 \mathrm{hr}$ & 0.06 & 0.16 & -0.02 & 0.14 & 0.06 & -0.08 & 0.24 & $0.42^{2}$ & $-0.65^{3}$ & 0.14 \\
\hline 4 days & & -0.21 & 0.02 & 0.22 & -0.32 & & 0.09 & 0.43 & -0.54 & $-0.74^{1}$ \\
\hline 2 wk & & & 0.29 & $-0.43^{2}$ & -0.15 & & & $0.47^{2}$ & -0.13 & -0.17 \\
\hline $12 \mathrm{wk}$ & & & & -0.25 & -0.19 & & & & $-0.51^{1}$ & 0.32 \\
\hline $16 \mathrm{wk}$ & & & & & -0.11 & & & & & 0.15 \\
\hline \multicolumn{11}{|l|}{ Both } \\
\hline $5 \mathrm{hr}$ & 0.19 & 0.05 & 0.04 & -0.23 & -0.05 & 0.15 & 0.21 & 0.21 & $-0.40^{1}$ & 0.08 \\
\hline 4 days & & -0.29 & -0.03 & -0.18 & $-0.48^{1}$ & & 0.10 & 0.25 & -0.34 & $-0.46^{2}$ \\
\hline $2 \mathrm{wk}$ & & & -0.01 & -0.07 & -0.09 & & & 0.23 & -0.01 & -0.27 \\
\hline $12 \mathrm{wk}$ & & & & -0.10 & 0.14 & & & & -0.19 & 0.34 \\
\hline 16 wk & & & & & 0.02 & & & & & 0.17 \\
\hline
\end{tabular}

${ }^{1} P 0.05$.

${ }^{2}$ Close to required level but not significant.

${ }^{3} P 0.01$. 
naturally suspicious when a series of nonsignificant differences tends to be unidirectional, and in Fig. 5, 10 of the 12 comparisons favor the female.

Mann-Whitney $\mathrm{Z}$ tests for the longitudinal and cross-sectional design group differences were not significant up to 12 weeks of age, and beyond that point the incidence of 0 scores is extremely high for both groups. The ratio of gasps to total sounds shows progressive decline from $44 \%$ at 4 weeks of age to $0 \%$ at 16 weeks and thereafter.

In our previous study (15) using a different sample, the reliability of the cry from age to age was examined at eight successive ages from $10 \mathrm{~min}$ to $96 \mathrm{hr}$ of age. Intercorrelations for the Cry Index (CI: a composite of the separate measures) were significantly reliable up to and including 2 days of age, and more so for the high rather than the low Apgar infants. Beyond that none of the intercorrelations were significant. In order to study the question of reliability in the present investigation, the Cl was computed for each of the six major points of change in the course of crying activity: $5 \mathrm{hr}, 4$ days, $2,12,16$, and 52 weeks. The $\mathrm{CI}$ is obtained by adding the longest cumulative time to the total number of sounds including gasps. In order to assign a higher score to the infant with a lower threshold, it was arbitrarily decided to deduct $5 \%$ of the total for each stimilus required to produce $60 \mathrm{sec}$ of crying. Latency is studied separately.

The intercorrelations are presented in Table 6 . The results are given for each sex separately since there were a number of instances in which the algebraic signs of the coefficients were opposite. Negative relations appear to be predominant where early versus later comparisons are made for males as well as females, but in either case most of the coefficients are not significant. Three of the $15 \mathrm{Cl}$ comparisons were significant or nearly significant for the males, and 6 of the 15 latency comparisons were significant or nearly so for the females. The overall picture presents no immediately discernible pattern of significance for either or both sexes combined. Identical coefficients may be marked as significant in one instance and not in another because the number of subjects, for whom data was available at both ages being compared, varies. The same coefficients were computed for each of the separate measures of the CI but they are not presented since they add little to the total picture.

Although the low intercorrelations may be traceable to the lack of predictive stability of the cry measures from age to age, they may also be due, in part, to repetitive scores. At the early ages most infants yielded $60 \mathrm{sec}$ of crying, especially since they were given three chances to do so, and at the later ages, the incidence of no response was quite high. In addition to the frequency of repetitive scores, one might also list as attenuating factors, the relative homogeneity of the sample, and the fact that all of the subjects were normal infants.

If the lack of stability of individual differences from age to age prevents the clinician from making predictions regarding the relative position of a given subject within his group at successive ages, the significance of mean differences found among the different age levels provides the ground for evaluating the overall development of the cry. Wilcoxon $T$ values for the significance of inter-age differences are presented in Table 7 for the $\mathrm{CI}$ and for latency.

In that table, positive $T$ values indicate that the older of the two age levels being compared has the larger mean. Most of the comparisons for each measure are statistically significant. Thus, the cry changes significantly from age to age, even though an individual subject may not maintain his relative position within group. If one were to combine the observations of the previous study already mentioned (15) at ages 1 min, $10 \mathrm{~min}, 2 \mathrm{hr}$, and $4 \mathrm{hr}$, with those of the present study, a description of the course of crying activity in normal infants for the first year of life might run as follows. The vigorous and lusty cry of the newborn tends to lose some of its force within
Table 7. Wilcoxon $T$ values for significance of interage differences

\begin{tabular}{cccccc}
\hline & \multicolumn{5}{c}{ Cry Index } \\
\cline { 2 - 6 } & \multirow{5}{*}{4 days } & $2 \mathrm{wk}$ & $12 \mathrm{wk}$ & $16 \mathrm{wk}$ & $52 \mathrm{wk}$ \\
\hline Cry Index & & & & & \\
$5 \mathrm{hr}$ & $+29.0^{1}$ & $+107.0^{2}$ & +123.0 & -115.0 & -105.5 \\
$4 \mathrm{days}$ & & -116.0 & $-36.0^{1}$ & $-39.0^{2}$ & $-24.0^{3}$ \\
$2 \mathrm{wk}$ & & & -180.5 & $-97.0^{2}$ & $-69.0^{2}$ \\
$12 \mathrm{wk}$ & & & & $-69.0^{3}$ & $-80.0^{1}$ \\
$16 \mathrm{wk}$ & & & & & +128.5 \\
Latency & & & & & \\
$5 \mathrm{hr}$ & -33.5 & -147.5 & $+45.0^{2}$ & $+65.5^{2}$ & $+20.5^{2}$ \\
$4 \mathrm{days}$ & & +86.0 & $+19.5^{2}$ & $+40.5^{2}$ & $+24.5^{3}$ \\
$2 \mathrm{wk}$ & & & $+80.5^{2}$ & $+78.5^{2}$ & $+56.5^{2}$ \\
$12 \mathrm{wk}$ & & & & +85.0 & $+29.5^{4}$ \\
$16 \mathrm{wk}$ & & & & & $+75.5^{2}$ \\
\hline
\end{tabular}

${ }^{1} P<0.05$

${ }^{2} P<0.01$

${ }^{3} P<0.02$

${ }^{4} \mathrm{~T}$ required at $P 0.05=29.0$.

the first few hours of life. The vigor of the cry returns in the hospital nursery period with a rhythmic cadence, rapid gasping for air, and a faster reaction time to stimulation. From 2 weeks to 12 weeks the cry is somewhat stable with respect to heightened sensitivity and audible output. It then begins to taper off in terms of its strident and demanding nature to a point near 16 weeks of age and thereafter, which suggests the replacement of purely reflexive action with a maturing suppressive mechanism. Doubtless, the changes in the cry are manifestations of corresponding changes in the development of the infant with respect to a variety of factors including lung capacity, vocal chord and velar control, myelinization of nerve fibers, and, eventually, complete cerebral integrity.

It has already been mentioned that the mean IQ of the present sample is significantly higher than that of the general population. In order to test the hypothesis that the present findings should be restricted only to a high IQ group, the 38 longitudinal subjects were dichotomized on either side of their combined median IQ of 119 , and the curves for all measures were plotted once again for each group separately. At the six major points of change in the courses of the curves for the combined group. The 19 subjects above the median, whose scores ranged from 120 to 149 , had a mean IQ of 130.5, SD 9.4, while the 19 subjects below the median with scores ranging from 81 to 118 had a mean IQ of 106.5, SD 12.5. Although the relation of IQ to crying activity will be treated at length in a separate paper, it should be pointed out that the courses of the cry reaction curves were similar in both the high and the lower IQ groups. The same trends already seen in the figures presented above were also found in the dichotomized groups.

\section{SUMMARY}

The critical findings of this study may be summarized as follows. (1) Although there is considerable variability in the crying response to painful stimulation at any of the age levels specified in the present study, reactivity is lowered at $5 \mathrm{hr}$ of age, increases at 2 days of age, and then remains relatively stable up to 12 weeks. Thereafter, it diminishes markedly, or at the least, the overt cry reaction is suppressed. (2) That the course of the cry reaction curves is primarily a function of age is supported by additional findings reported here which rule out as major determinants systematic adaptation effects, sex 
differences, and gross differences in IQ levels within the group studied.

\section{REFERENCES AND NOTES}

1. Bell, R. Q.: Some factors to be controlled in studies of the behavior of newborns. Biol. Neonatorum, 5: 200 (1963).

2. Bell, R. Q.: and Haaf, R. A.: Irrelevance of newborn waking states to some motor and appetitive responses. Child Develop. 42: 69 (1971)

3. Bell, S. M., and Ainsworth, M. D. S.: Infant crying and maternal responsiveness. Child Develop., 43: 1171 (1972).

4. Blinick, G., Tavolga, W. N., and Antopol, W.: Variations in birth cries of newborn infants from narcotic-addicted and normal mothers. Amer. J. Obstet. Gynecol., 110: 948 (1971).

5. Bowlby, J.: Attachment and loss. In: Attachment, Vol. 1 (Basic, New York, 1969).

6. Brackbill, Y.: Cumulative effects of continuous stimulation on arousal level in infants. Child Develop., 42: 17 (1971).

7. Cohen, D.: The crying newborn's accomodation to the nipple. Child Develop., 38: 89 (1967).

8. Desmond, M. M.: Personal communication.

9. Fisichelli, V. R., Coxe, M., Rosenfeld, L., Haber, A., Davis, J., and Karelitz, S.: The phonetic content of the cries of normal infants and those with brain damage. J. Psychol., 64: 119 (1966).

10. Fisichelli, V. R., Haber, A., Davis, J., and Karelitz, S.: Audible characteristics of the cries of normal infants andthose with Down's Syndrome. Percept. Mot. Skills, 23: 744 (1966).

11. Fisichelli, V. R., and Karelitz, S.: The cry latencies of normal infants and those with brain damage. J. Pediat., 62: 724 (1963).

12. Fisichelli, V. R., and Karelitz, S.: Frequency spectra of the cries of normal infants and those with Down's Syndrome. Psychonomic Sci., 6: 4 (1966).

13. Fisichelli, V. R., and Karelitz, S.: The effect of stimulus intensity on induced crying activity in the meonate. Psychonomic Sci., 16: 6 (1969).

14. Fisichelli, V. R., Karelitz, S., Eichbauer, J., and Rosenfeld, L. S.,: Volume-unit graphs. Their production and applicability in studies of infants' cries. J. Psychol., 52: 423 (1961)

15. Fisichelli, V. R., Karelitz, S., and Haber, A.: The course of induced crying activity in the neonate. J. Psychol., 73: 183 (1969.).

16. Fleener, D. E., and Cairns, R. B.: Attachment behavior in human infants; Discriminative vocalization on maternal separation. Develop. Psychol., 2: 215 (1970).

17. Formby, D.: Maternal recognition of the infant's cry. Develop. Med. Child Neurol., 9: 293 (1967).

18. Friedman, H.: Magnitude of experimental effect and a table for its rapid estimation. Psychol. Bull., 70: 245 (1968).

19. Glass, G. V., and Stanley, J. C.: Statistical Methods in Education Psychology (Prentice-Hall, Englewood Cliffs, N. J. 1970).

20. Hart, B. M., Allen, E. K., Buel, J. S., Harris, F. R., and Wolf, M. M.: Effects of sc ial reinforcement on operant crying. J. Exp. Child Psychol., 1: 145 (1964).

21. Karelitz, S., and Fisichelli, V. R.: The cry thresholds of normal infants and those with brain damage; An aid in the early diagnosis of severe brain damage; J. Pediat., 61: 679 (1962).

22. Karelitz, S., and Fisichelli, V. R.: Infants' vocalizations and their significance. Clin. Proc. Child Hosp., 25(11): 345 (1969).

23. Karelitz, S., Fisichelli, V. R., Costa, J., Karelitz, R., and Rosenfeld, L.: Relation of crying activity in early infancy to speech and intellectual development at age three years. Child Develop., 35 : 769 (1964)

24. Karelitz, S., Fisichelli, V. R., Davis, J., and Haber, A. \& The role of crying activity in Apgar scoring: Intercomparisonsilamong the signs of the Apgar scale. J. Amer. Med. Ass., 198:318 (1966).

25. Karelitz, S., Karelitz, R. F., and Rosenfeld, L. S.: Infants' vocalizations and their significance. In: P. W. Bowman and $H$. V. Mautner: Mental Retardation, Proceedings First International
Medical Conference, p. 439 (Grune \& Stratton, New York, 1960).

26. Kraemer, H. C., Korner, A. F., and Thoman, E. B.: Methodological considerations in evaluating the influence of drugs used during labor and delivery on the behavior of the newborn. Develop. Psychol., 6: 128 (1972).

27. Lind, J.: Newborn infant cry. Acta Paediat. Scand. Suppl., 163 (1965).

28. Lind, J., Wasz-Hockert, O., Vuorenkoski, V., and Valanne, E.: The vocalization of a newborn, brain-damaged child. Ann. Paediat. Fenn., 11: 32 (1965).

29. Matheny, A. P., and Brown, A. M.: The behavior of twins: Effects of birth weight and birth sequence. Child Develop., 42: 251 (1971).

30. McCarthy, D.: Language development in children. In: L. Car michael: Manual of Child Psychology (J. Wiley \& Sons, New York, 1954).

31. Moss, H. A., Robson, K. S., and Pedersen, F.: Determinants of maternal stimulation of infants and consequences of treatment for later reactions to strangers. Develop. Psychol., $1: 239$ (1969).

32. O'Doherty, N.: A hearing test applicable to the crying newborn infant. Develop. Med. Child Neurol., 110: 380 (1968).

33. Ottinger, D. R., and Simmons, J. E.: Behavior of human neonates and prenatal maternal anxiety. Psychol. Rep., 14: 391 (1964).

34. Pratt, K. C.: The Neonate. In: L. Carmichael: Manual of Child Psychology (J. Wiley \& Sons, New York, 1954).

35. Precht1, H. F. R., Thorell, K., Gramsberger, A., and Lind, J.: A statistical analysis of cry patterns in normal and abnormal newborn infants. Develop. Med. Child Neurol., 11: 142 (1969).

36. Provence, S., and Lipton, R. C.: Infants in Institutions. (International Universities Press, New York, 1962).

37. Ringel, R. L., and Kluppel, D. D.: Neonatal crying: A Normative Study. Folia Phoniat., 16:1 (1964).

38. Siegel, S.: Nonparametric Statistics for the Behavioral Sciences (McGraw-Hill, New York, 1956).

39. Simner, M. L.: Newborn's response to the cry of another infant Develop. Pschol., 5: 136 (1971).

40. Sockloff, A. L., and Edney, J. L.: Some extension of Student's t and Pearson's $r$ central distributions, Technical Report 72-5 (Measurement and Research Center, Temple University, Philadelphia, 1972).

41. Stechler, G.: Newborn attention as affected by medication during labor. Science, $144: 315$ (1964).

42. Terman, L. M., and Merrill, M. A.: Stanford-Binet Intelligence Scale, Third Revision (Houghton-Mifflin, Boston, 1960).

43. Valanne, E. H., Vuorenkoski, V., Partanen, T. J., Lind, J., and Wasz-Hockert, O.: The ability of human mothers to identify the hunger cry signals of their own-born infants during the lying-in period. Experentia, 23: 768 (1967).

44. Wasz-Hockert, O., Lind, J., Vuorenkoski, V., Partanen, T., and Valanne, E.: The Infant Cry (Spastics International Medical Publications, London, 1968).

45. Swingline, Inc. 32-00 Skillman Avenue Long Island City, N.Y.

46. The authors are grateful to Mrs. B. Haber for her assistance in all phases of the project, to the volunteers of the Womens Service Guild of the Long Island Jewish Hospital for their dedicated efforts in behalf of the study, and to Mr. Sidney Shapiro, R.B.P. F.B.P.A., for his technical assistance in preparing the figures.

47. Supported in large part by a grant from the National Institutes of Health, no. R01-HD 00332 with S. Karelitz as Principal Investigator, and V. R. Fisichelli as Co-Principal Investigator. Additional financial support was given by Mrs. Norman Tishman, Mrs. Julius S. Loewenthal, and several other friends who prefer to remain anonymous.

48. Requests for reprints should be addressed to: V. R. Fisichelli, Ph.D., Office of S. Karelitz, M.D., Emeritus Director of Pediatrics, Long Island Jewish-Hillside M.C., New Hyde Park, N. Y. 11040 (USA)

49. Accepted for publication July 9, 1974 